\title{
МИКРОБИОЛОГИЧЕСКАЯ И ЭНЗИМОЛОГИЧЕСКАЯ КОНВЕРСИЯ РАСТИТЕЛЬНЫХ ОТХОДОВ С ЛИГНОЦЕЛЛЮЛОЗНОЙ СТРУКТУРОЙ
}

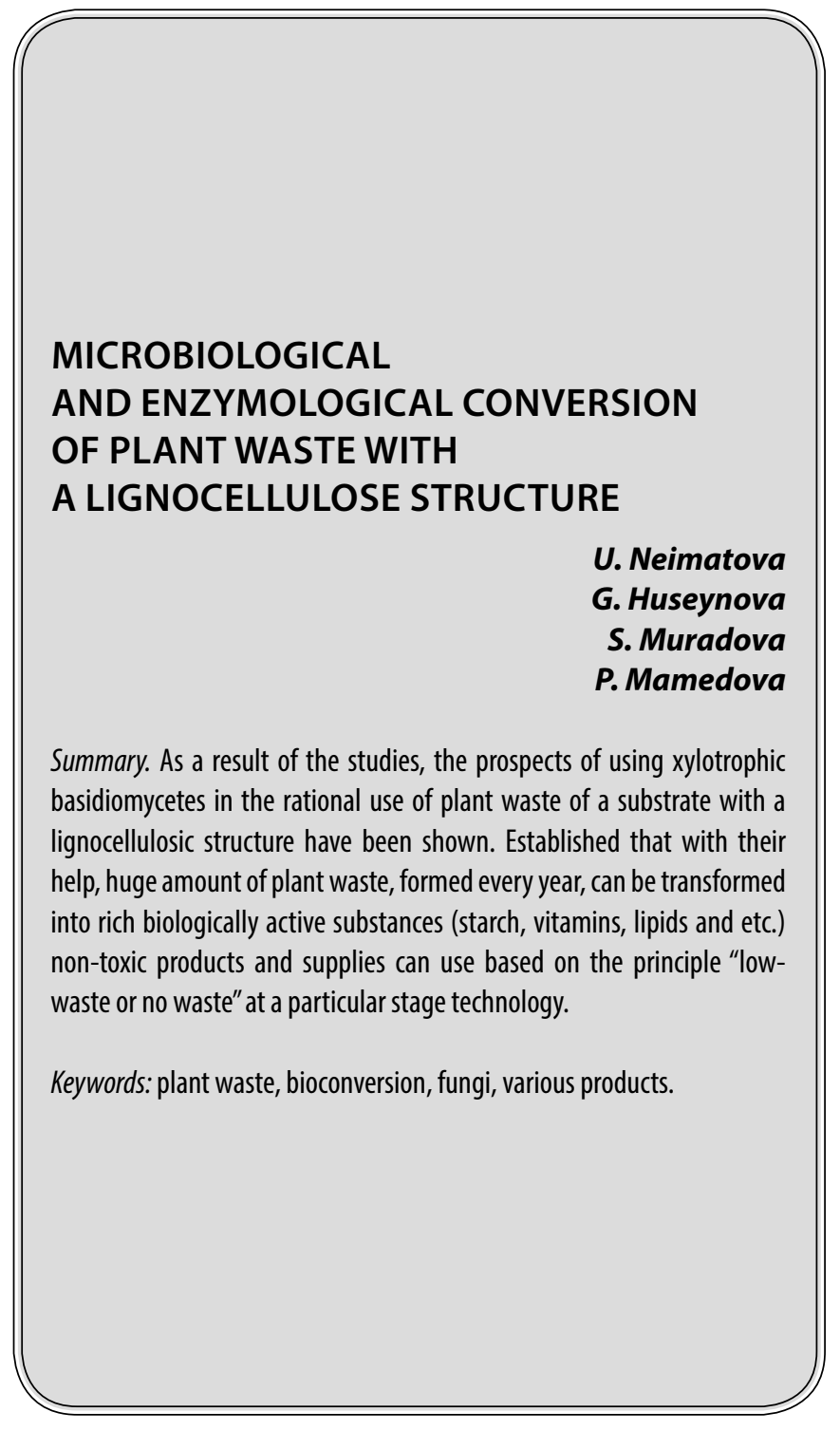

H ежелательные экологические изменения в природной среде и возрастающая ограниченность сырьевых ресурсов, всё актуальнее ставит вопрос о разработке экологически безопасной технологии переработки растительных отходов, которые являются крупнотоннажными, и служат основной причиной загрязнения окружающей среды[8, 12, 14]. В настоящее время современная биотехнология предлагает разные подходы для решения этой проблемы, среди которых наиболее перспективным является биоконверсия, прежде всего микробиологическая и энзимологическая [7]. При этом лигноцеллюлозные отходы, являющиеся еже-
Нейматова Улкер Вагиф кызы

Диссертант, Институт Микробиологии НАН Азербайджана, г. Баку azmbi@mail.ru

Гусейнова Гюлнар Иса кызы Докторант, Институт Микробиологии НАН Азербайджана, г. Баку gulnar_muel@mail.ru

Мурадова Севда Магеррам кызы Преподаватель, Азербайджанский Государственный Педагогический Университет, г. Баку sevdamuradova3@gmail.com

Мамедова Парвин Мирдамат гызы Диссертант, Институт Микробиологии НАН Азербайджана, г. Баку peri.omar87@gmail.com

Аннотация. В результате проведенных исследований показана перспективность использования ксилотрофных базидиомицетов в рациональном использовании растительного субстрата с лигноцеллюлозной структурой. Установлено, что с их помощью огромное количество растительных отходов, образующихся каждый год, можно преобразовать в богатые биологически активные вещества (крахмал, витамины, липиды и др.) нетоксичные продукты и материалы, которые можно использовать по принципу «малоотходность или без отходов» на определенном этапе технологии.

Ключевые слова: растительные отходы, биоконверсия, грибы, различные продукты.

годно возобновляемыми и обладающие практически неисчерпаемым источником энергии, в условиях истощающихся ресурсов, становятся перспективным сырьем для производства разнообразных полезных веществ и продуктов, важных для жизни и благосостояния людей.

Проведенные в этой области многочисленные исследования убедительно показали, что ксилотрофные грибы, особенно их представители, относящиеся к базидиомицетам, обладают всеми необходимыми свойствами для рациональной утилизации растительных отходов[7-8, 13, 16]. 
Однако, из-за отсутствия соответствующей материально-технической и научной базы, они до сегодняшнего дня не нашли полного, и эффективного применения.

В связи с этим, целью представленной работы явилась разработка способов, позволяющих рационально использовать растительные отходы, в соответствии с вышеуказанными задачами.

\section{Материалы и мето $\Delta$ ы}

В ходе работы было использовано около 50 штаммов ксилотрофных базидиальных грибов, выделенных из экологически разных территорий (лесов расположенных в Большом Кавказском хребте, Талышских горах) Азербайджанской Республики. Выделение штаммов грибов в чистую культуру проводили по общепринятым методам [6] на сусло-агаре(20 Б) из плодового тела гриба, собранного из указанных территорий Азербайджана. Идентификации грибов осуществляли по известному определителю[3].

В качестве лигноцеллюлозного субстрата были использованы: древесные (широколиственные и хвойные) опилки, подсолнечная лузга, и др. отходы, которые образуются в аграрном секторе Азербаджана.

Биоконверсию растительных субстратов, определения активности ферментов (целлюлаза, ксиланаза, амилаза, пектиназа, протеаза, липаза, лакказа и пероксидаза), получение частично очищенных ферментных препаратов и изучение их молекулярных параметров проводили согласно методу[3-6, 9-11, 15], который в настоящее время используется для аналогичных работ.

\section{Полученные результаты}

и их обсужАения

В ходе работы первоначально проведен скрининг ксилотрофных базидиальных грибов, по способности трансформировать отходы в продукт кормового назначения. Полученные результаты показали, что штаммовая вариабельность по всем критериям (потеря веса, разложение целлюлозы и лигнина, накопление белка, урожайность, распределение общего урожая по волнам плодоношения и др.), которые использовали для оценки эффективности процесса, в рамках одного рода или вида превышает родовые или видовые различия по этому показателю. Несмотря на обнаруженные отличия, полученные результаты показали, что для биоконверсии отходов в продукт кормового назначения целесообразно использование грибов Bjerkandera adusta P-40, Pleurotus ostreatus F-118, Polyporus aqariceus F-17, Trametes hirsuta M-5 и T.versicolor D-13, кото- рые по продуктивности и биохимической характеристике превосходят все исследованные ксилотрофные грибы.

Сложность и многоплановость решения проблемы биоконверсии растительных материалов в первом случае требует интенсификации процесса разложения растительного сырья и изучения условий, ускоряющих процесс расщепления основных компонентов растений: целлюлозы и лигнина. В исследованиях, проведенных в связи с оптимизацией процессов микробиологической конверсии отходов отобранными грибами, было установлено, что только добавление в среду $\mathrm{NH}_{4} \mathrm{NO}_{3}$ во всех случаях стимулирует процессы конверсии растительных отходов, а $\mathrm{NaNO}_{3}$ - значительно ослабляет разложение целлюлозного компонента и повышает разложение лигнина до 1,2 раза. Грибы более эффективно трансформируют отходы в обогащенный белком продукт при температуре выращивания $28^{\circ} \mathrm{C}$, при исходном значении влажности 64-67\% и рН среды 5,2-5,6. Изучение химического состава продуктов, полученных в оптимизированной по всем параметрам условиях, показали, что они являются продуктами, не обладающими токсичностью, обогащенными различными физиологически активными веществами и имеют высокую переваримость по сравнению с исходным субстратом. Кроме того, количество нуклеиновых кислот в полученном продукте в пределах допустимой нормы составляет 0,17-0,20\% и по содержанию незаменимых аминокислот соответствует требованиям ФАО. Все это является резким аргументом доказывающим, что полученные продукты могут быть использованы в кормовых целях.

Результаты исследований, посвященные изучению физиолого-биохимических и биотехнологических основ ферментативной активности ксилотрофных макромицетов, показали, что все исследуемые ксилотрофы проявляют активность гидролитических ферментов, хотя при этом уровень активности конкретного фермента сильно варьировал, в зависимости от использованного гриба и субстрата, хотя гидролитический потенциал грибов B. adusta P-40 и P. ostreatus F-118区 был относительно высоким, что явилось основой для выбора их, в качестве активного продуцента гидролаз. При изучении активности оксидаз было установлено, что ферментативную активность проявляют только те культуры, которые в природных условиях вызывают белую гниль. У грибов в определенной мере прослеживается связь между активностью гидролазы и оксидазы, и формой отношения к субстрату, на котором он обитает в природных условиях. Кроме того, уровень активности лакказы у всех грибов всегда выше, чем у пероксидазы. В качестве активных продуцентов являются грибы C.unicolor $M-3$ T.hirsute M-5 и T.versicolor D-13. 
При оптимизации условий установлено, что синтез целлюлазы, амилазы, ксиланазы у грибов B. adusta P-40 и P. ostreatus F-118 происходит индуктивно и контролируется катаболитной репрессией, хотя в отличие от классически индуцибельных ферментов они имеют достаточно высокий базальный уровень, что видимо, связан с адаптацией к обитанию на одревесневших субстратах. Что касается оксидазы, то установлено, что согласно классическому соображению, синтез окислительных ферментов у грибов C.unicolor M-3, T.hirsuta D-5 и T. versicolor $D-13$, следует принимать за конститутивный, так как при использовании любого источника на среде обнаруживается внеклеточная активность всех окислительных ферментов.

В ходе исследований также показано, что грибы, отобранные в качестве активных продуцентов оксидаз, C.unicolor $M-3$, T.hirsute $M-5$ и T.versicolor D-13 способны также разлагать чистый лигнин, выделенный из лигноцеллюлозных отходов, хотя при этом грибы между собой отличались также по интенсивности разложения лигнина и по изменению активности окислительных ферментов. Синтез лакказы у всех грибов соответствовал разложению лигнина с начала до конца ферментации. Такая зависимость не так ярко, но наблюдалась и по активности лигниназы. Между разложением лигнина и активностью пероксидазы такой связи не намечается. Например, через 2 сутки разложение лигнина у гриба C.unicolor $M-3$ составило 1,2\%, но при этом гриб не проявлял пероксидазную активность. Однако через определенное время интенсивность синтеза пероксидазы у всех грибов нарастает и по скорости она опережает все ферменты. Все эти данные дали основание считать, что в отличие от пероксидазы, лакказа является участником процесса деградации лигнина с самого начала.
В ходе работы также исследованы возможности получения частично очищенного ферментного препарата из отобранных грибов. Результаты показали, что полученные препараты обладают более широким спектром ферментов (целлюлаза, ксиланаза, амилаза, пектиназа, протеаза, лакказа, пероксидаза, лигниназа и т.д.) и они характеризуются такими кинетическими (малой чувствительностью к ингибированию, высокой адсорбционной способностью и др.) параметрами, которые необходимы для эффективной утилизации отходов путем энзимологической конверсии для практических нужд. Кроме того, установлено, что эффективность при использовании ферментных препаратов широкого спектра действия тесно связана с соотношением уровней активности пектиназы и целлюлазы в ферментных препаратах и это является фактором, обусловливающим эффективность процесса ферментативного гидролиза растительных субстратов.

\section{Зак^ючение}

Проведенные исследования убедительно показали, что ксилотрофные базидиальные грибы обладают всеми необходимыми свойствами для рациональной утилизации растительных отходов, на основе которых была разработана малоотходная комплексная технология, предусматривающая использование растительных отходов и ресурсов по принципу «мало- или безотходной технологии на конкретном этапе». Кроме того, на основе проведенных нами работ и анализа литературных данных разработана схема, отбора активного продуцента окислительных ферментов и получение ферментного препарата лигнолитического действия, сущность которого заключалась в точности результата первичного отбора и сокращении процесса по времени, и затраты энергии.

\section{ЛИТЕРАТУРА}

1. Биология ксилотрофных базидиомицетов: структура и функции /Под ред. (тороженко В.В., Крутова В.И., Селочник П.Н. Москва-Петрозаводск, 2000,324 с.

2. Бондарцева М.А. Определитель грибов России. Порядок афиллофоровые. СП.: Наука, 1998, вып. 2, 391с.

3. Ермаков А.И. (под ред.) Методы биохимических исследований растений, Л.: Колос, 1972, 456 с.

4. Клесов А.А. Ферменты целлюлозного комплекса. Проблемы биоконверсии растительного сырья, М.: Наука, 1986. С. 93-136. 6

5. Лабораторный практикум по технологии ферментных препаратов. М.: Легкая и пищевая промышленность, 1982, $240 \mathrm{c}$.

6. Методы экспериментальной микологии (Под. ред. Билай В.И.) Киев: Наукова думка, 1982, 500с.

7. Мурадов П.З. Особенности ферментативной активности ксилотрофных грибов в процессе биоконверсии растительных отходов. Автореферат диссертации на... д.б.н. Баку, 2004, 48с.

8. Мурадов П.З. и др. Ксилотрофные грибы, как активные деструкторы растительных отходов.//Вестник МГОУ, серия «Естественные науки», 2009, № 1, c. $109-112$.

9. Нетрусов А.И., Егорова М.А., Захарчук Л.М., Колотилова Н.Н. и др. Практикум по микробиологии. М.: Издательский центр «Академия», 2005, 608с.

10. Полыгалина Г.В., Чередниченко В.С. и др. Определение активности ферментов. Справочник. М.: ДеЛи принт, 2003, 375с.

11. Шарков В.И., Куйбина Н.И., Соловьев Ю.П., Павлова Т.А. Количественный анализ растительного сырья. Москва: Лесная промышленность, 1976, $72 c$.

12. Guerriero, G., Hausman, J.F., Strauss J. et al. Lignocellulosic biomass: biosynthesis, degradation and industrial utilization.// Eng.Life Sci., 2016, v.16, p.1-16.

13. Hoeksma, J., Misset, T., Wever, C. et al. A new perspective on fungal metabolites: identification of bioactive compounds from fungi using zebrafish embryogenesis as read-out// Sci Rep., 2019, 9, 17546 (2019). https://doi.org/10.1038/s41598-019-54127-9 
14. Kumar, A., Gautam, A. and Dutt, D. Biotechnological Transformation of Lignocellulosic Biomass in to Industrial Products: An Overview. Advances in Bioscience and Biotechnology, 2016, v.7, p.149-168.

15. Kumkum A., Feroza H., Md Abdul H. Screening of cellulase, pectinase and xylanase activities and optimization of radial mycelial growth of two thermophilic fungi// Bangladesh J. Bot., 2013, v.42(2), p.207-213

16. Leonowicz A., Cho N.-S., Luterk J., Wilkolazka A. et al. Fungal laccase: properties and activity on lignin.// J. Basic Microbiol., 2001, v. 41, p.185-227. 15

17. Rodríguez-Couto, S. Industrial and environmental applications of white-rot fungi// Mycosphere, —2017, 8(3), -p.456-466

( ) Нейматова Улкер Вагиф кызы ( azmbi@mail.ru ), Гусейнова Гюлнар Иса кызы ( gulnar_muel@mail.ru ),

Мурадова Севда Магеррам кызы ( sevdamuradova3@gmail.com ),Мамедова Парвин Мирдамат гызы ( peri.omar87@gmail.com ).

Журнал «Современная наука: актуальные проблемы теории и практики»



